seconds. This already high clegree of precision was, however, surpassed in the particular section under notice. Thus over a total of sixty-eight triangles the average closing error was $0^{\circ} 63^{\prime \prime}$ and the maximum error of any one triangle $r{ }^{\prime \prime} 6^{\prime \prime}$. This pitch of excellence was moreover attained without any increase of time spent at the stations; indeed, it is claimed, we think with justice, that the arc establishes a " record," both technically and financially. The average cost per point occupied was, in fact, lower than has been attained with any previous work of the same class, and as, owing to the nature of the country, high and expensive signal scaffolds were necessary, it seems that the reduction made in the cost of the actual observing was even more notable than appears on first inspection.

This conveys a lesson which may be taken to heart by those responsible for future survey operations. It seems clear that the difference in method of execution between what we are accustomed to call first order or primary triangulation (i.e. triangular error under $\mathrm{I}^{\prime \prime}$ ) and secondary work (triangular error under $3^{\prime \prime}$ ) lies mainly in the nature of the signals. If lamps only are used it is a matter of indifferen se as regards rate of progress, and hence as regards cost, whether a large instrument capable of first order precision or a smaller one capable only of second order is used. In either case one observer can complete the observations at a station in one night, and no reduction in size of instrument, in number of rounds taken, or in order of accuracy will enable him to do more. The difference in cost of transport between the two instruments is in most cases negligible. The only extra cost involved is that caused by the necessity of providing five lampmen or lamp parties and moving them from point to point. In rough country this might undoubtedly prove a formidable addition, but in the case of future boundary commissions or land surveys in Africa it is anyhow worth serious consideration whether a backbone or net of primary triangulation, planned so as to fit in with a comprehensive geodetic scheme, cannot be undertaken without a prohibitive increase in expenditure.

This is the sort of question for which the coordinated experience and authority of a geodetic institute would prove invaluable, and it is to be hoped that it will not be long before such an institution, long overdue, is established in England for the British Empire.
E. H. H.

\title{
Science and Research in the Air Service.
}

$\mathrm{T}^{\mathrm{H}}$ E Air Estimates for the year 1920-2I, recently presented to Parliament, show a total estimated expenditure of 2 I million pounds compared with 54 million pounds in the previous year. The apparent saving in cost is 33 millions, but it is really greater, for in the year 1919-20 the cost of the experimental and research services was borne jointly by the Admiralty and the Ministry of Munitions, and is now wholly included in the Air Ministry vote.

As regards the Royal Air Force, the number of officers, warrant officers, non-commissioned officers, airmen, and boys provided on the establishment (exclusive of those serving in India) has fallen from 150,000 in $1919-20$ to rather less than 30,000 in $1920-2 \mathrm{I}-\mathrm{a}$ striking reduction. The 2I million pounds for the new financial year includes rather under a million for civil aviation and two and a half millions for experiment and research. This latter sum would have been more than three millions $(3, \mathrm{I} 77,000 l$. $)$ had not an "appropriation in aid," due to the sale of certain airships for $600,000 l$, , come to the relief of the vote. The actual figures are as follows :-

Liquidation of war liabilities ...

... I, 334,000

Works, buildings, and lands ... $\quad \ldots \quad$ I 40,000

Aeronautical inspection $\quad \ldots . \quad \ldots \quad 80,300$

Airship constructional establishment...

R.A.E., Farnborough $\ldots$... $\ldots$

Technical equipment and materials ...

Salaries and wages

Miscellaneous

$\begin{array}{lll}\ldots & \ldots & \cdots \\ \cdots & \cdots & \cdots\end{array}$

315,000

401,200

844,390

48,800

13,850

An expenditure of more than three millions for research alone in a single year would appear to be a generous provision, but an examination of the foregoing figures shows that much of the expenditure will not be employed for this purpose.

The air vote for meteorological services has risen from $12,000 l$. in $1919-20$ to $77,629 l$. in 1920-2I, and part of this will doubtless be used in research work of some kind, though these services are not part of the research directorate, but come under the civil aviation side of the Air Ministry. The sum of $77,629 l$. includes the provision of only $358 l$. for " experimental stations," which is such a very modest amount that we as sume experimental research in meteorology is provided for by other aid. In any event, the amount cannot represent the degree to which at tention is given to research, since in meteorology there is ample scope for original work based upon the observations from what may be termed routine stations.

The printed Estimates convey the intention of the Government to make liberal provision for research in aeronautics, but it is impossible to determine precisely what sum of money is thereby devoted solely to "experiment and research," since such work is sometimes carried on at the ordinary air stations. Moreover, 40,00ol. for the National Physical Laboratory is not borne on the Air Estimates at all, but on those for the Civil Service. The Estimates do, however, include the sum of $20,340 l$. for research "grants to scientific bodies," and 600,00ol. as an encouragement to invention. 